\title{
Differences between Chinese and American University Education from the Perspective of Curriculum Design -- Taking the University of Minnesota as an Example
}

\author{
Haiping Li \\ Beijing Institute of Petrochemical Technology, Beijing 102617, China
}

Funding: This paper is a key project of "student-centered" education and teaching reform and research at the university level "Research on the teaching paradigm reform of accounting" (NoZd20160401).

About the author: Haiping Li (1980 -), born in Chifeng, Inner Mongolia, is a visiting scholar of ondon South Bank University. She is an associate professor and director of accounting department of Beijing Institute of petroleum and chemical technology.

\begin{abstract}
More and more educational researchers pay attention to the differences between China and the United States. Although the educational concepts of China and the United States respect "student-centered", and are very close in educational system and institutional setting, they are still similar in curriculum design. Taking the University of Minnesota Twin Cities as an example, this paper makes a detailed comparative analysis from the four aspects of curriculum objectives, curriculum assessment, teaching activities and syllabus, finds out the essential differences between Chinese and American university curriculum design, and puts forward that the change of Chinese university curriculum design concept needs to start from basic education, and the cultivation of teachers' thinking and ability is the key influence of the reform factor.
\end{abstract}

Key words: Differences in education between China and the United States; Curriculum objectives; Course assessment; Teaching activities; Teaching program

Publication date: April, 2021; Publication online: 30 April, 2021

*Corresponding author: Haiping Li, 378782440@qq.com

After several years of development, China's university education has made great progress, but the "fever of studying in the United States" has continued to heat up, and even the phenomenon of low age in the United States has become a popular trend. However, why do students who enjoy Chinese traditional culture spend a lot of money to challenge American education? On the surface, this can be caused by the rapid development of China's economy and the pursuit of high-quality education It is an inevitable trend that young people will study in the United States. For a long time, many domestic educators and educational institutions have paid attention to the differences between China and the United States in education. Therefore, China's university education is constantly learning and absorbing the innovative ideas of
American education, and carrying out education system reform, including MOOC class and flipped classroom in recent years. The author participated in a one-month training program of teachers' professional development and teaching team building in the University of Minnesota. In the process of learning, the author found that both the teacher development and student education in China and the United States are very close to each other in terms of assessment management, educational administration system and teaching philosophy, but there are still some inherent "magnetism" in curriculum design Essential difference. Therefore, from the perspective of curriculum design and assessment, this paper takes the curriculum design of University of Minnesota Twin Cities as an example to compare the differences between 
Chinese and American university education, in order to provide reference value for Chinese University Education on how to design a course and the direction of design reform.

\section{Key elements model of curriculum design}

Fink integrated curriculum design model (Figure 1) is one of

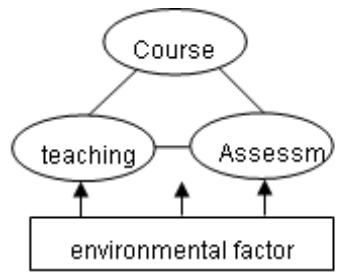

Fiqure 1. Model of inteqratina

the more classic models, which gives the key elements of curriculum design. Based on this model, other integrated models appear later. According to Fink model, the key elements of curriculum design include learning objectives, assessment and feedback, teaching activities and environmental factors.

Curriculum objectives, that is, to complete the course learning, what students can get; Teaching activities, which teaching activity design can achieve the curriculum objectives; Assessment and feedback, how to test students to achieve learning objectives in class;

Environmental factors include five aspects: first, the specific environment of teaching and learning, such as the number of students, the form of class, the weekly frequency of classes, the level of students faced by the course, etc; Second, the general learning environment, such as the position of the curriculum in the training program; The third is the nature of the curriculum itself, such as the theory course, the practice course, the important transformation conflict in the curriculum field, etc; The fourth is the characteristics of the students, such as the students' prior knowledge of the course, what the students' learning expectations are, etc. the fifth is the characteristics of the teachers, such as the teachers' values about "teaching" and "learning", the teachers' attitude towards the course and the students, and the teachers' advantages in teaching, etc. The four aspects are closely related to each other.

\section{Comparison of curriculum design differences}

The model of key elements of curriculum design has shown that it includes three key elements: curriculum objectives, curriculum assessment and teaching activities. Environment has an important influence on the above three elements, and the three elements are important components of curriculum syllabus. Therefore, we take the University of Minnesota Twin Cities as an example to compare the differences in four aspects: curriculum objectives, curriculum assessment, teaching activities and syllabus.

\subsection{Comparison of curriculum objectives}

Both Chinese and American universities follow the same concept of "student-centered", but they give different interpretations of "curriculum objectives".

\subsubsection{The expression structure is different}

As shown in Table 1, in American educational philosophy, curriculum objectives can be interpreted as students' learning objectives, and the contents clarify students' gains after learning. It is one of the main reference standards for American college students to choose courses. Students understand the gains of curriculum learning through curriculum objectives in advance, and then decide whether to choose the course. Therefore, the curriculum objectives are written by the teachers, and will be closely related to the personal teaching philosophy and experience of the teachers. Each teacher should design the curriculum objectives in combination with various environmental factors.

The form adopted in China is "what teachers teach + what students are required to master", which is written by the person in charge of the course. It is a unified standard for different teachers to teach the same course. Therefore, teachers are more concerned about curriculum objectives than students. This difference is due to the fact that American courses are mainly students' free choice of courses, while most courses in China are compulsory courses. Therefore, the setting of curriculum objectives in China has become the assessment standard for schools to assess whether teachers have the ability or are good at teaching a certain course.

The root cause is closely related to the development of education in China and the United States. American education originated from imparting knowledge to the nobility. Later, social development began to pay attention to professional education, but it was still based on "thick general education" and combined with personal interests to develop professional education. Therefore, the most effective way to change the fate of knowledge through mass education is to instill knowledge in the past.

On the differences of curriculum objectives between China and the United States

(1) Above the expression structure: In the United States, it is the harvest of students' learning, while in China, it is the 
content of teachers' teaching + requiring students to master the content.

(2) In the use of words: The United States is concrete, vivid and measurable, while China lays emphasis on the list of knowledge points.

(3) In terms of the scope of the objectives: The United States is relatively broad, while China is relatively narrow.

\subsubsection{The use of words is different}

The description of curriculum objectives in the United States emphasizes the use of "concrete, vivid and measurable" words.

For example: Knowledge level: Students will learn; Application level: Students will be able to do; Through this course, students acquire some specific thinking, skills, complex project management skills, etc. The description of curriculum objectives in China mainly focuses on the listing of knowledge points, and requires students to master and understand these knowledges.

\subsubsection{Scope of objectives}

American education goals advocated "meaning learning", namely to consider how long a course from the spiritual level to influence students, students in addition to the previous knowledge, application and combined with real life and so on, also including the spirit level, such as the humanities concern dimension, prompting students to create new values, interests, what affect the students care about, to learn how to study, and the impact will be lasting effects (Figure 2). So the goals are very broad.

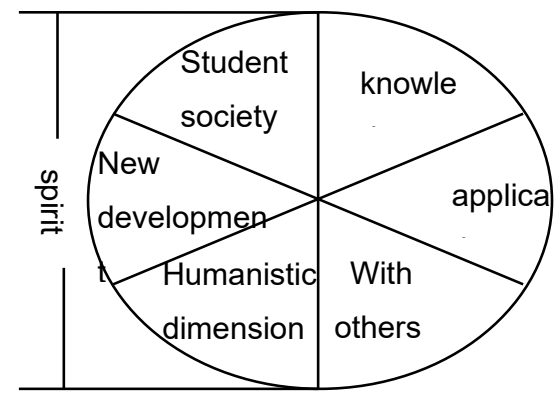

Figure 2. Scope of Objectives

However, the scope of China's university education curriculum objectives mainly stays in knowledge, application and other aspects are combined, and the former two are the main ones, There is no spiritual concern. Therefore, the scope of the target is relatively narrow.

To sum up, by comparing the differences of curriculum objectives, we can find the curriculum in the United States. It is student-centered, focusing on the development of human nature and people's adaptability to the environment training. From the perspective of professional certification, China's curriculum has begun to focus on students. However, there is a lack of consideration for the spiritual level, but whether the curriculum objectives can be realized from the true. In the sense of "student-centered", the biggest challenge is the participation and attention of students.

\subsection{Comparison of course assessment differences}

The general assessment types include process assessment and result assessment. There are many assessment forms, such as objective questions, case analysis, group discussion, etc. The curriculum assessment methods in China and the United States are quite similar, and the common ones in Chinese universities are as follows: Final $* \%+$ usual $* \%$. Among them, the proportion of ordinary performance is $10 \%-30 \%$, emphasizing the result evaluation.

However, the curriculum assessment in the United States is biased towards process assessment. It is considered that the result assessment is a high-risk assessment method for students, so it should be used with caution. In addition to the common assessment methods in China, there are also some special common assessment methods

\subsubsection{Rating scale}

The scale is also commonly used in American courses, which is mainly used to assess students' mastery of basic knowledge, proficiency in applied knowledge, and students' interest in learning. Teachers will design the scale according to the curriculum objectives, and attach the scale to students' homework. On the one hand, it can give timely feedback to students, and at the same time, it can be used as the basis for teachers to score and defend themselves.

\subsubsection{Cards}

American teachers pay attention to the feedback of students in each class. They usually send cards to students at the end of each class. First, what knowledge points do you doubt in this lesson? Second, what knowledge did you learn in this lesson. On the one hand, the role of in class cards is as a student's usual assessment, on the other hand, they can provide timely feedback with students. For common problems with more feedback, they can be explained again after class by video recording.

\subsubsection{Electronic story}

Encourage students to record the life content related to the course through electronic audio and video, collect materials and display them. This kind of assessment method can feedback students' spiritual gains. 


\subsubsection{Folder}

Whether it's electronic homework or paper homework, students can choose their own important and meaningful homework and logs, and collect them in a special folder to find the parts that students get the most from this course.

\subsubsection{Students' self evaluation}

After the students' homework is finished, the teacher first asks the students to score by themselves, and then compares the students' score with the teacher's score to see the students' cognitive ability. For the content with more cognitive deviation, the students' understanding is weak. The teacher will further discuss and explain this part with the students.

\subsubsection{Scene evaluation}

Set up a specific situation, let the students put what they have learned into the future. For example, in geography class, students' learning of Malaysian geography is assessed. The traditional assessment method is to set objective questions what are the geographical characteristics of Malaysia? And scenario evaluation - suppose you are a branch manager of IBM, and you are sent to Malaysia, what astronomical, geographical and human factors do you need to analyze in Malaysia to help the development of IBM branch? Through the comparison of the above assessment methods, it can be found that the purpose of Chinese assessment method is to evaluate whether the students have reached the pre-set standards in the curriculum objectives, which belongs to the review evaluation. The assessment mainly focuses on knowledge, and the feedback of assessment results is not timely; In the strict sense, the assessment method in the United States is a kind of feedback, that is, feedback on what students have gained in the course learning, and feedback on themselves from teachers. Therefore, it is an educational evaluation, with regular assessment, timely feedback and comprehensive consideration of the spiritual level.

\subsection{Comparison of teaching activities}

China's education is indoctrination type, and the teaching activities are mainly to teach knowledge, while American education is guidance type. In the United States, the teaching activities are mainly students' hands-on participation, forming the teaching activities of "preview before class, test in class, small experiment in class, classroom summary".

(1) Students are assigned homework and scored after class;

(2) First of all, check whether students have done the preview of knowledge points before class, and score.One is to know whether to do homework preview before class by testing; Second, to understand the understanding degree of knowledge points, and to choose and explain knowledge points with emphasis;

(3) In class, small experiments are designed to deepen students' understanding and application of knowledge, and generate new values, interests and other spiritual levels. In class, small experiments are mainly designed to stimulate students' interests, without scoring. The main way of quiz or experiment is the cooperative learning method of think pair share proposed by Professor Frank Lyman of Maryland University for the first time, which gives students time and process to think, and enables students to learn to discuss and solve problems.

(4) Encourage students to summarize before the end of each class, including sharing notes with students, recording what they have gained and what they are confused about.

\subsection{Comparison of syllabus layout}

Curriculum objectives, assessment methods and teaching activities constitute the contents of the syllabus. The following gives a detailed comparison of the contents of the syllabus between China and the United States.

\subsubsection{Course Description}

The United States is described from four aspects. (1)The goal of the course is to learn "you can The general description of the "general description". (2)Students' learning methods include the learning time and material preparation that students need to spend in and out of class. (3)Classroom teaching methods, that is, how teachers and students complete classroom activities together; (4)Students' learning philosophy, that is, what philosophy students need to learn in this course, such as active thinking, computational philosophy, critical thinking, etc. Description method: It is described by "Tian" structure. China is described in two ways. (1)Course objectives, a brief description of the main teaching content of this course. (2)Students' learning achievements: It is usually described by a piece of text with a fixed structure, for example: This course teaches what; Through this course, students need to understand what; Understand; Master.

\subsubsection{Teacher information}

The United States has teachers' basic information, teaching characteristics, class time and place, while China does not.

\subsubsection{Course objectives, module decomposition}

The first mock exam module is divided into 3 modules, each module. China, on the other hand, does not.

\subsubsection{Students' learning and American output content}

The first mock exam is what each student can learn from each module. In the first mock exam, each module can decompose 
multiple learning output contents. China, on the other hand, does not.

\subsubsection{Teaching materials and reference materials}

U.S.A: (1)It is shown in the cover photo image. (2) There is no specific teaching material, but many reference books are given. (3) The reference materials also include teachers' personal research papers or classic papers. In China: (1) List one textbook and several reference books in the form of words.

(2) A textbook, a number of reference books.

\subsubsection{Course schedule}

In the United States, there are: (1)List presentation; (2)Content arrangement of each class; (3)Content completed by students in each class. The course content is a further detailed subdivision of the course objective module, covering all the specified reference materials. In China: (1)How many class hours does each course need to complete. (2)The content of the course is set by the chapters of the textbook.

\subsubsection{Course assessment method}

The final score of the United States is divided according to a and B grades. There is a detailed scoring list, which clearly lists what students need to do if they want to get a grade, and gives specific scoring standards. China's final score is mainly given according to the percentage system, listing the proportion of the usual score and final score.

\subsubsection{Teaching content}

The United States does not have it, while China uses the textbook chapter directory as a reference, listing the specific knowledge points of each chapter in detail, as well as the requirements for students, that is, to understand, understand and master.

\subsubsection{Display form}

In order to improve the reading effect of students in the United States, the number of A4 paper is no more than 4 pages. But in China, the description is pure text, A4 paper, the number of at least four pages.

\subsubsection{Graphic display content}

In the United States, there are photos of the teaching process and the cover of recommended books to stimulate students' interest in the course, while in China, there are no photos.

By comparison, it can be found that the curriculum in American universities is student-centered. Therefore, the syllabus is designed from the perspective of students, presented with both pictures and texts, and is direct and clear, which is in line with students' reading habits. While the syllabus in China is designed from the perspective of teachers, advocating standard templates, which aims to require different teachers to teach the same course according to the requirements According to the content of the syllabus, it is a constraint on the teachers.

\section{The Enlightenment of comparative differences in curriculum design on China's education}

In American curriculum design, we can find that they infiltrate the concept of product and customer into curriculum design. Curriculum is a product, students are customers, and teachers are product designers. Therefore, the design of curriculum needs to stand in the perspective of student customers. At the same time, in the actual design process, students, as customers, will examine the whole process of product design to determine whether they need to design Choose this course and what I can gain from it.

Teachers have the challenge risk of being questioned and reviewed by students, so they need to spend many times of time to design the syllabus to stimulate students' interest in the course (that is, the product). Finally, they need to accept students' evaluation of their own teaching results (that is, the evaluation of product effectiveness). Therefore, curriculum design includes all aspects of product development, production and after-sales evaluation, and teachers need to participate in it personally Every link.

Students are very clear-cut target customers, know what they need, syllabus such as product instructions or operation guide, students understand the course through the syllabus, but whether they can get the best product function effect depends on the cooperation of students and teachers in the specific course teaching process. Therefore, to truly realize the student-centered curriculum design, all aspects need to reflect the close cooperation between teachers and students.

\subsection{The change of curriculum design concept needs to start from basic education}

Student participation is the core of student-centered. American students' habit of autonomous learning is from kindergarten and primary education to university education. Their educational philosophy is the same, and they are all guided teaching. However, Chinese education has always been indoctrination education, that is, the learning habit of accepting knowledge cultivated by 12 years of primary and secondary education. Students are not interested in participating in the classroom and are used to the teacher's indoctrination of knowledge, which is one of the main bottlenecks of China's university education reform.

\subsection{The cultivation of teachers' thought and ability is another key to the reform}


What the United States is facing is not to change teachers' thinking, but to improve teachers' ability to guide students. The challenge of students is the most "dangerous" signal for American teachers, which urges teachers to take teaching as a research topic. However, there are many problems in China. Changing teachers' indoctrination, cultivating teachers' guiding ability and promoting teachers' teaching research power and ability are the key to realize the goal of teaching Another key to education reform. Therefore, encouraging teachers to teach with a research attitude is another important key to realize the reform of curriculum design, because whether the differences in cultural backgrounds of different countries will affect the effect of a certain teaching activity, etc. These are extremely important research topics in carrying out education reform.

\subsection{The change of teachers' ideas needs the support of relevant policies}

Through the teacher training at the University of Minnesota Twin Cities, every faculty member (including the teacher center, library, academic affairs office, etc.) finds that they all take their own work as the starting point and study how to improve their working ability. Every job is a kind of service, with a sense of service, to improve their service level has become the goal of every teaching staff. The study of how to improve their service ability has produced a series of research results, and these research results are closely combined with the reality and promoted. Then, in the context of China's specific education system, teachers' compensation comes from financial allocation, which has lost the source power of teaching research and only relies on the consciousness of "conscience teaching"; At the same time, under the pressure of scientific research assessment, Chinese universities seem to have entered the situation of "no research, no road, no status". In fact, this situation is extremely dangerous for Chinese university education. As a matter of fact, in addition to the famous research universities of Harvard and MIT, there are also well-known teaching liberal arts and science schools such as Wesleyan College in the United States. Therefore, the development of university education can be diversified, rather than competing for the scientific research ranking. The change of this idea needs the support and guidance of relevant education policies.

\section{References}

[1] Yuan QY, Ting T. The development process and trend of Chinese education in the United States in the new era $[\mathrm{J}]$. Contemporary Chinese History Studies,2015(1): 65-76.

[2] Pang SQ. Comparative study on curriculum and personnel training mode of mechanical specialty between China and the United States [J]. Chinese university teaching, 2007 (11): 8791.

[3] Tao M. Research on the change of American academic guidance system and its Enlightenment to China [J]. Higher education management, 2012 (3): 72-75.

[4] Du WM, Lou XH, Zheng CX, et al. Discussion on the training mode of Innovative Talents -- Based on the successful experience of Cornell University [J]. China forestry education, 2017(9): 96-98. 